\title{
Influence of intensive phonomotor rehabilitation on apraxia of speech
}

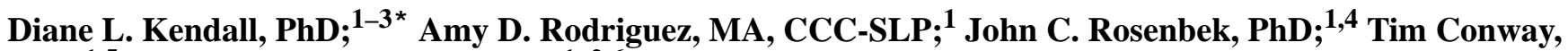 \\ PhD; ${ }^{1,5}$ Leslie J. Gonzalez Rothi, PhD ${ }^{1-2,6}$ \\ ${ }^{1}$ Department of Veterans Affairs (VA) Rehabilitation Research and Development Brain Rehabilitation Research Center, \\ Malcom Randall VA Medical Center (VAMC), Gainesville, FL; ${ }^{2}$ Department of Neurology, ${ }^{3}$ McKnight Brain Institute, \\ and Departments of ${ }^{4}$ Communicative Disorders and ${ }^{5}$ Clinical and Health Psychology, University of Florida, Gaines- \\ ville, FL, ${ }^{6}$ Geriatric Research, Education, and Clinical Center, Malcom Randall VAMC, Gainesville, FL
}

\begin{abstract}
In this phase I rehabilitation study, we investigated the effects of an intensive phonomotor rehabilitation program on verbal production in a 73-year-old male, 11 years postonset a left-hemisphere stroke, who exhibited apraxia of speech and aphasia. In the context of a single-subject design, we studied whether treatment would improve phoneme production and generalize to repetition of multisyllabic words, words of increasing length, discourse, and measures of self-report. We predicted that a predominant motor impairment would respond to intensive phonomotor rehabilitation. While able to learn to produce individual sounds, the subject did not exhibit generalization to other aspects of motor production. Discourse production was judged perceptually slower in rate and less effortful, but also less natural. Finally, self-report indicated less apprehension toward speaking with unfamiliar people, increased telephone use, and increased ease of communication.
\end{abstract}

Key words: aphasia, apraxia of speech, discourse production, mental practice, multisyllabic words, phoneme production, phonomotor rehabilitation, repetition, verbal production, words of increasing length.

\section{INTRODUCTION}

Acquired apraxia of speech (AOS) in adults is a controversial disorder. AOS typically results from a lefthemisphere stroke and concurs with aphasia; it has been defined as a "phonetic-motoric disorder of speech production caused by inefficiencies in the translation of wellformed and filled phonological frame to previously learned kinematic parameters assembled for carrying out the intended movement, resulting in intra- and interarticulator temporal and spatial segmental and prosodic distortions" [1]. Clinical observations of AOS can include difficulty in articulatory (e.g., substitutions, distortions, distorted substitutions, repetitions), rate and prosody (e.g., slow utterances, prolonged consonants and vowels, silent pauses, equalized stress, restricted pitch), and fluency (e.g., false starts, restarts, visible and audible trial-and-error groping, sound and syllable repetitions) aspects of speech [2].

Since the first investigational report of treatment for AOS was published over 30 years ago [3], a variety of treatment techniques have emerged [4]. Wambaugh completed a comprehensive review of 42 investigations of AOS treatment spanning 1973 to 2002 [4]. This review shows that AOS treatments are generally assigned to one of three categories: articulatory positioning (e.g., integral

Abbreviations: AOS $=$ apraxia of speech, ITSACORR = independent time series analysis of autocorrelated data, $\mathrm{KP}=$ knowledge of performance, $\mathrm{KR}=$ knowledge of results, $\mathrm{RR} \& \mathrm{D}=$ Rehabilitation Research and Development, VA = Department of Veterans Affairs, WAB = Western Aphasia Battery.

* Address all correspondence to Diane L. Kendall, PhD; VA Rehabilitation Research and Development Brain Rehabilitation Research Center, Malcom Randall VA Medical Center, Box 151A, 1601 SW Archer Rd, Gainesville, FL 326081197; 352-376-1611, ext 5238; fax: 352-379-2332. Email: kendadl@neurology.ufl.edu

DOI: 10.1682/JRRD.2005.11.0175 
stimulation, repeated practice, articulatory placement cuing, sound-contrast practice, oral-muscular phonetictarget restructuring prompts), prosodic (e.g., metronomic pacing, finger tapping, contrastive stress), or augmentative (e.g., gestures, writing, computerized systems, communication boards). Further, most treatments were motivated by symptoms of the disorder rather than theoretical notions about the underlying mechanism of impairment.

In this investigation, treatment was motivated by the theoretical notion that AOS (1) is an inability to produce skilled motor actions [5], (2) is a motor-level disorder of well-formed phonological representations, and (3) impairment at this level is, in part, due to retrieval and sequencing of previously learned movement patterns [5]. We propose that by intensively training movement patterns starting at a phoneme level and incorporating concepts of motor learning [5], retrieval and sequencing of speech motor programs will improve and this improvement will be evident in speech production.

Schmidt and Bjork define motor learning as the "process of acquiring the capability for producing skilled actions" achieved through practice and experience and discuss ways to optimize motor learning [5]. In particular, they talk about prepractice and acquisition stages. In the prepractice stage, the subject should be motivated, understand the task, be able to model movements, and demonstrate the task with knowledge of how a movement is produced. During the acquisition stage, conditions of stimulus presentation should vary to optimize motor learning and, ultimately, generalization. Also, random practice of stimuli is recommended over blocked trials; even though random practice depresses performance during training, performance is often facilitated on later tests of generalization [5]. The notion of random conditions is contrary to common practice, where stimulus presentation and practice are typically delivered in blocked trials.

Mental practice, or thinking about an activity, has been shown to increase learning. Schmidt and Bjork talk about two types of feedback during the acquisition stage: knowledge of results (KR) and knowledge of performance (KP) [5]. KR refers to feedback about the outcome of a movement pattern with reference to the environmental goal, and KP refers to feedback about specific aspects of the movement (e.g., biofeedback). In regard to the delivery of KR, a short delay between subject performance and feedback is recommended over a large delay. The large delay actually inhibits learning, and filling the delay may produce detrimental effects on performance and learning.
KR summarized over a number of trials in a series has been shown to promote motor learning over immediate KR.

We incorporated these just-mentioned principles [5] into a program traditionally designed for the rehabilitation of phonological awareness in children with dyslexia (Lindamood Phoneme Sequencing Program) [6]. This program served as a basis for our treatment because we feel it develops phonological and motor articulatory skills, starting at the phoneme level and building to multiple phonemes with nonwords. To isolate motor speech systems and target this type of knowledge in training, we feel training with nonword stimuli is desirable. While the treatment program is outlined in detail in the Appendix (available online only at http://www.rehab.research.va.gov/), a brief overview relating motor principles to the treatment is provided here.

The treatment begins with a prepractice phase. In this phase, examples are provided about how oral movements are depicted in the treatment pictures. A cartoon drawing of the brain illustrating "pathways" between the articulatory, auditory, and visual centers of the brain is shown. During the acquisition phase, conditions of stimulus presentation are varied to optimize motor learning. The stimuli (e.g., line drawings) are randomly practiced across auditory discrimination, verbal production, and tactile/kinesthetic modalities. The stimuli are also varied within articulatory placement (e.g., contrasting two lip sounds) and between placements (e.g., lip vs tongue sounds). Mental practice, which has been shown to increase skill learning, is a key component of this program. A Socratic questioning method is employed, which requires the subject to "think about" both correct and incorrect productions. For example, when the subject was shown a mouth picture of $/ \mathrm{k} /$ and incorrectly produced $/ \mathrm{p} /$, the therapist would say, "What I heard you say was $/ \mathrm{p} /$. Does $/ \mathrm{p} /$ sound like $/ \mathrm{k} /$ ?” The subject is cued to look in the mirror and repeat $/ \mathrm{k} /$ and $/ \mathrm{p} /$ and realize they produced two different sounds. The therapist holds up the picture of $/ \mathrm{k} /$ to his/her mouth, produces $/ \mathrm{k} /$, and asks the subject if the picture and the sound match. The subject says "Yes." The therapist reinforces how the tongue is moving in the picture and in the mouth. The therapist asks the subject to again produce the sound that corresponds with the picture. The subject now correctly produces $/ \mathrm{k} /$. Finally, Schmidt and Bjork recommend short-delay KR and KP [5]. In terms of KR, immediate, intermittent feedback for both correct and incorrect productions is provided. The therapist encourages KP by asking the subject to use a mirror and monitor the majority of sound productions. 
This phonomotor treatment approach was employed in a previous investigation for rehabilitation of acquired alexia in two individuals with aphasia and AOS from lefthemisphere stroke [7]. Subject 1 demonstrated severe AOS characterized by single-word utterances with struggling, groping, and an inability to repeat phonemes or words with fewer errors in automatic speech (e.g., counting) compared with volitional speech, while subject 2 had a milder form of AOS and struggled to produce individual phonemes. In the context of a single-subject multiplebaseline design, both participants received pre- and posttreatment assessments and repeated treatment, generalization, and control probes. Posttreatment results showed improved verbal production for both subjects in terms of improved repetition, spontaneous speech, and oral praxis.

The aim of the present study was to continue investigating the effects of this treatment program in a single individual with acquired AOS and aphasia. The primary research questions were-

- Research Question 1: Does phonomotor treatment improve the ability to produce individual phonemes?

- Research Question 2: Do phonomotor treatment effects generalize to repetition of multisyllabic real words and words of increasing length?

- Research Question 3: Do phonomotor treatment effects generalize to measures of perceptual judgment of discourse production by unbiased speechlanguage pathologists and subject self-report?

\section{METHODS}

\section{Subject Description}

The subject was a 73-year-old right-handed man with 12 years of education who experienced a left-hemisphere stroke 11 years prior to the onset of this study. The magnetic resonance imaging scan taken at initiation of this study shows involvement in much of the frontal lobe, including the opercular cortex and portions of Wernicke's area (Figure 1). Prior to his stroke, the subject was a professional singer, songwriter, and acoustic/steel guitar player. At the time of this study, he lived alone and was independent in all activities of daily living except reading and writing. The subject signed a University of Florida and Department of Veterans Affairs (VA) medical center approved informed consent form (form 545-99) prior to testing and treatment. A summary of the most relevant

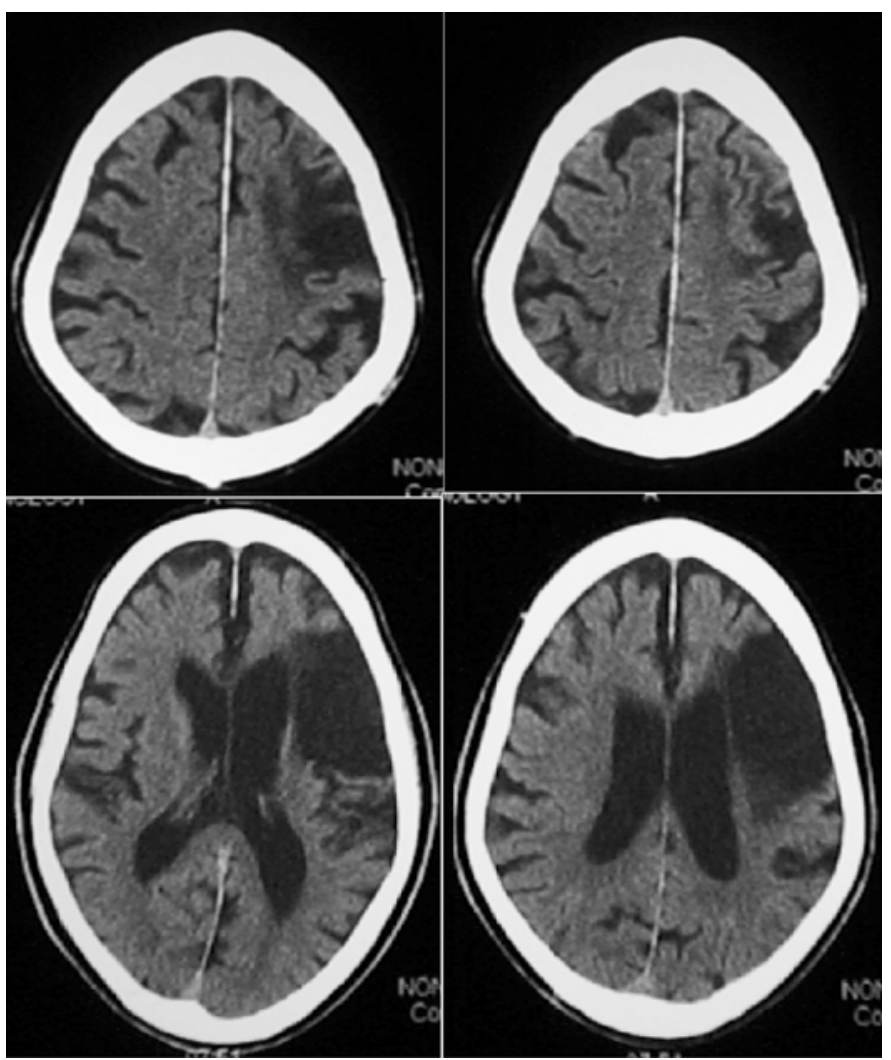

Figure 1.

Magnetic resonance imaging of 73-year-old male subject at time of treatment.

findings of speech, language, and phonomotor evaluations conducted at the time of this study is presented in Table 1.

As evidenced by his performance on the Western Aphasia Battery (WAB) [8] (Aphasia Quotient $=81.6$ / 100 ), the subject displayed a mild Broca's aphasia and relatively spared auditory comprehension in the context of nonfluent verbal output characterized by agrammatism, word retrieval failures (anomia in discourse and confrontation naming), and motor articulatory difficulty. Motor speech characteristics included articulatory struggling/ groping during individual sound repetition, errors in voice/ voiceless contrasts, vowel prolongations, and intraword schwa intrusions. These characteristics indicated moderate AOS [2]. For oral-motor movements, he showed difficulty initiating and repeating movements such as coughing, puffing out cheeks, protruding tongue, etc. His voice was hoarse. Endoscopic examination of the larynx was normal. 
Table 1.

Summary of pre- and posttreatment standardized test results of 73-year-old male subject.

\begin{tabular}{|c|c|c|c|}
\hline Test & Pretreatment & Posttreatment & Total Possible \\
\hline \multicolumn{4}{|l|}{ Western Aphasia Battery [1] } \\
\hline Aphasia Quotient & 81.6 & 85.7 & 100 \\
\hline Fluency & 5 & 6 & 10 \\
\hline Yes/No Questions & 60 & 60 & 60 \\
\hline Auditory Word Recognition & 60 & 60 & 60 \\
\hline Repetition & 79 & 98 & 100 \\
\hline Object Naming & 60 & 56 & 60 \\
\hline Word Fluency & 9 & 8 & 20 \\
\hline Sentence Completion & 10 & 10 & 10 \\
\hline Response Speech & 10 & 10 & 10 \\
\hline $\begin{array}{l}\text { Alternate Phonologic Awareness Composite Score } \\
\text { (blending nonwords, segmenting nonwords) }\end{array}$ & 55 & 61 & - \\
\hline Pyramids and Palm Trees (raw score) [4] & 47 & 50 & - \\
\hline $\begin{array}{l}\text { Lindamood Auditory Conceptualization } \\
\text { (total converted score) [5] }\end{array}$ & 70 & 91 & 100 \\
\hline \multicolumn{4}{|c|}{$\begin{array}{l}\text { 1. Kertesz A. The Western Aphasia Battery. New York (NY): Psychological Corporation; } 1982 . \\
\text { 2. Kaplan E, Goodglass H, Weintraub S. The Boston Naming Test. Philadelphia (PA): Lippincott Williams \& Wilkins; } 1983 . \\
\text { 3. Wagner RK, Torgesen JK, Alexander C. The Comprehensive Test of Phonological Processing. Austin (TX): PRO-ED Inc; } 1999 . \\
\text { 4. Howard D, Patterson KE. The Pyramids and Palm Trees Test. Bury St. Edmunds (England): Thames Valley Test Company; } 1992 . \\
\text { 5. Lindamood CH. Lindamood Auditory Conceptualization test. Austin (TX): Teaching Resources; } 1971 .\end{array}$} \\
\hline
\end{tabular}

\section{Treatment Description}

The rehabilitation program was administered intensively (4-5 days/week, 2 hours/day for a total of 104 hours of therapy over 14 weeks). The treatment protocol is outlined in detail in the Appendix. Treatment termination was determined by the subject's schedule. At the time of this study, he lived out of state and moved to Gainesville, Florida, for a limited time to participate in the treatment protocol.

\section{Experimental Design and Data Analysis}

A multiple-baseline single-subject design was used. The subject initially received a series of diagnostic tests (Table 1). Prior to treatment administration, stable baselines were established for repeated treatment, generalization, and control probes. Probes were readministered after every 8 hours of treatment (weekly); however, because of unforeseen circumstances such as illness, treatment probes were primarily administered after 6 to 8 hours of treat- ment, with one probe administered after 16 hours of treatment. We randomized the order of probe administration each week to prevent potential order effects. No feedback regarding accuracy of performance was given during probe sessions. One week after treatment termination, weekly probes and language measures were readministered. Pre- and posttreatment assessments were administered and scored online by an unbiased, experienced speech-language pathologist who was uninvolved in this study. Maintenance testing 1 week after treatment termination was not possible because the subject resided in a different state.

To answer Research Question 1 (Does phonomotor treatment improve the ability to produce individual phonemes?), we presented 16 isolated phonemes represented by line drawings of articulators. The subject was shown one picture at a time and asked to produce the sound illustrated (e.g., /b/). Responses were scored as correct/ incorrect in an online record by a speech-language 
pathologist blinded to the study. Incorrect productions were defined as phonemic substitution, distortion, or errors in voicing. Percent accuracy for phoneme production was calculated and graphed accordingly.

Research Question 2 (Do phonomotor treatment effects generalize to repetition of multisyllabic real words and real words of increasing length?) focused on effects of treatment generalization to mechanisms of speech-motor programming. To answer this question, we used repeated probes of repetition of multisyllabic words (e.g., snowman, snowman, snowman) and words of increasing length (three sets of three words: cat, catnip, catapult) (Figure 2). The subject was asked to repeat the words after the clinician, and responses were audio taped with a Marantz tape recorder (PMD 430, Mahwah, New Jersey) and Crown headset microphone (CM 312, Elkhart, Indiana). Responses were later digitized with computerized speech software (Computerized Speech Laboratory, model 4300, KayPENTAX, Lincoln Park, New Jersey) so that broad phonetic transcription could be used to analyze correct production at the phoneme level. For words of increasing length, only the root word was analyzed across productions. We used this procedure to

\begin{tabular}{|cc|}
\hline Words of Increasing Length & Multisyllabic Words \\
\hline cat & animal \\
catnip & snowman \\
catapult & artillery \\
please & stethoscope \\
pleasing & rhinoceros \\
pleasingly & \\
thick & \\
thicken & \\
thickening & \\
\hline
\end{tabular}

Figure 2.

Repeated generalization probe stimuli (words of increasing length and multisyllabic words). examine potential detrimental effects programming additional syllables might have had on root-word production. In other words, "cat" was analyzed for accuracy across "cat," “catnip," and "catapult.” Incorrect productions were defined as semantic substitutions, phonemic substitutions, anticipations, reversals, distortions, and voicing errors. Accuracy for number of correctly produced phonemes for each root word was calculated and graphed accordingly.

To address Research Question 3 (Does phonomotor treatment generalize to measures of discourse production and subject self-report?), we performed two separate assessments. In the first, unbiased speech-language pathologists perceptually judged pre- and posttreatment discourse productions; the second was a questionnaire completed by the subject.

Data for discourse production in which two pictures were presented (one single picture and one picture sequence) were probed and discourse production was audio- and videotaped for later transcription [9]. A clinician uninvolved in this study transcribed each sample and verified accuracy by audiotape. Next, three unbiased judges were asked to rate pre- and posttreatment picture discourse production samples for eight different perceptual characteristics (rate, speaker effort, prosody, articulatory precision, ease of articulation, content, naturalness, and overall intelligibility) (Table 2). Samples were randomized so judges were naive to the order of treatment progression. Judges were asked to decide by comparing two samples (e.g., "Is there a difference in rate between sample $x$ and sample $y$ ? If yes, is sample $y$ faster or slower than sample $x$ ?”). Regarding intrajudge reliability, samples were shown to each judge three times and only intrajudge responses in agreement two of the three times were used.

The subject completed a questionnaire pre- and posttreatment. This questionnaire was an unstandardized scale that addressed communication apprehension, telephone use, ability of others to understand speech, and ease of

Table 2.

Results of perceptual analysis of discourse production posttreatment for each judge individually and consensus.

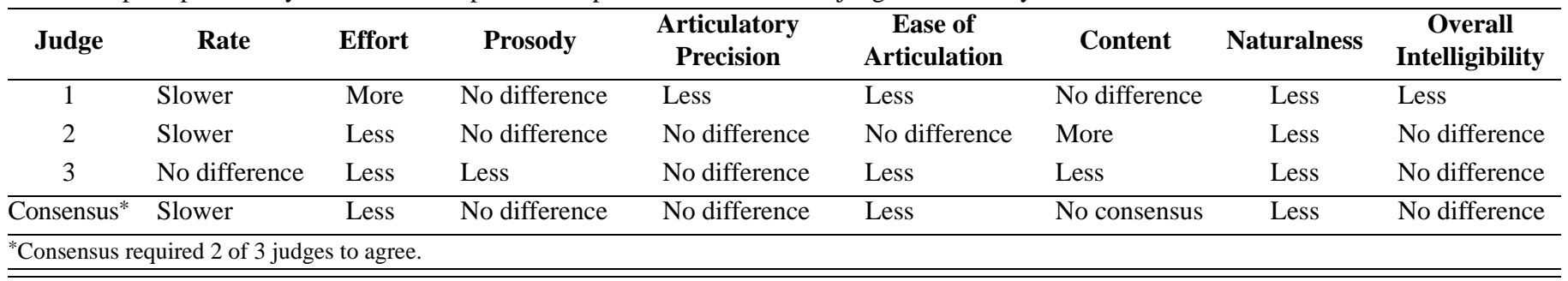


communication. The subject was asked to make a mark on a line from 0 to 100 percent in response to the following questions: What was your apprehension when speaking with unfamiliar people before therapy? What was your apprehension when speaking with unfamiliar people after therapy? What was your telephone use before therapy? What was your telephone use after therapy? What was the ability of a listener to understand you before therapy? What was the ability of a listener to understand you after therapy? What was your ease of communication before therapy? What was your ease of communication after therapy?

Interrater reliability was performed on repetition of multisyllabic words and words of increasing length by an independent judge uninvolved in this study on 15 percent of the subject's total productions. The specific data for this analysis included 10 words of increasing length plus 5 multisyllabic words repeated three times. Percentages were analyzed for reliability and reflected combined scores for these two tests. The scores from the judge were compared with the initial measurements made by the therapist who collected the repeated probe data. Intraclass correlation coefficients were calculated.

\section{RESULTS}

Figure 3 displays results for subject performance on treatment (Figure 3(a)), generalization to repetition of words of increasing length (Figure 3(b)), and control probes (Grooved Pegboard, Figure 3(c)). To determine magnitude of change relative to the timing of conditions in the treatment and generalization probes, we calculated an independent time series analysis of autocorrelated data (ITSACORR) [10] using all baseline points for the pretreatment phase and treatment/maintenance data points for the second phase. $P$-values on each graph reflect results from the ITSACORR calculation. ITSACORR yields a test of overall change and a test of change in slope and level. ITSACORR could not be calculated on the control probe data because of too few data points in the pretreatment phase.

\section{Research Question 1}

Research Question 1 asked, Does phonomotor treatment improve the ability to produce individual phonemes? Results of ITSACORR of repeated treatment probe of phoneme production in isolation were significant $\left(t_{(15)}=2.31\right.$, $p=0.02)$. Performance in baseline phase shows a slight increase for isolated phonemes; however, performance shows a dramatic increase once treatment is initiated.

\section{Research Question 2}

Research Question 2 asked, Does treatment generalize to repetition of multisyllabic words and words of increasing length? ITSACORR for multisyllabic words showed no difference $\left(t_{(11)}=-1.99, p=0.8\right)$. ITSACORR for words of increasing length showed a significant posttreatment difference for one-syllable words $\left(t_{(4)}=3.34, p=\right.$ $0.03)$ and no significance for two- $\left(t_{(4)}=2.09, p=0.11\right)$ and three-syllable words $\left(t_{(4)}=1.14, p=0.32\right)$ (Table 3).

\section{Research Question 3}

Research Question 3 asked, Does phonomotor treatment generalize to measures of discourse production and subject self-report? Pre- and posttreatment discourse samples were judged to show treatment effects: slower rate, less effort, less natural. No difference was noted in prosody, articulatory precision, content, and overall intelligibility, and a decrease in ease of articulation was reported. Posttreatment self-report showed that the subject was less apprehensive when speaking with unfamiliar people (100\% apprehension before therapy, $10 \%$ apprehension after therapy), had increased telephone use (used telephone $0 \%$ before therapy and $90 \%$ after therapy), and communicated more easily ( $0 \%$ ease of communication before therapy, $100 \%$ ease of communication after therapy).

\section{Pre- and Posttreatment Standardized Test Results}

Pre- and posttreatment results for the WAB showed a slight improvement in the overall Aphasia Quotient from $81.6 / 100$ to $85.7 / 100$. Relative to motor speech abilities, an increase in performance on the repetition (79/100 to $98 / 100)$ and fluency (5/10 to 6/10) subtests was not noted. No change was observed in performance on the Boston Naming Test (37/60 to 37/60) [11] or Pyramids and Palm Trees (47/52 to 50/52) [12]. Expected gains on test of phonological processing (Comprehensive Test of Phonological Processing [13] and Lindamood Auditory Conceptualization test [14]) were present.

\section{Interrater Reliability}

Interrater reliability results for combined performance scores on the multisyllabic words and words of increasing length showed the average percent correct from the therapist who collected online data was 65 percent. Average percent correct from the judge who performed reliability results was 60 percent correct (difference 5\%). Intraclass correlation coefficient for accuracy was 0.95 . 
(a)

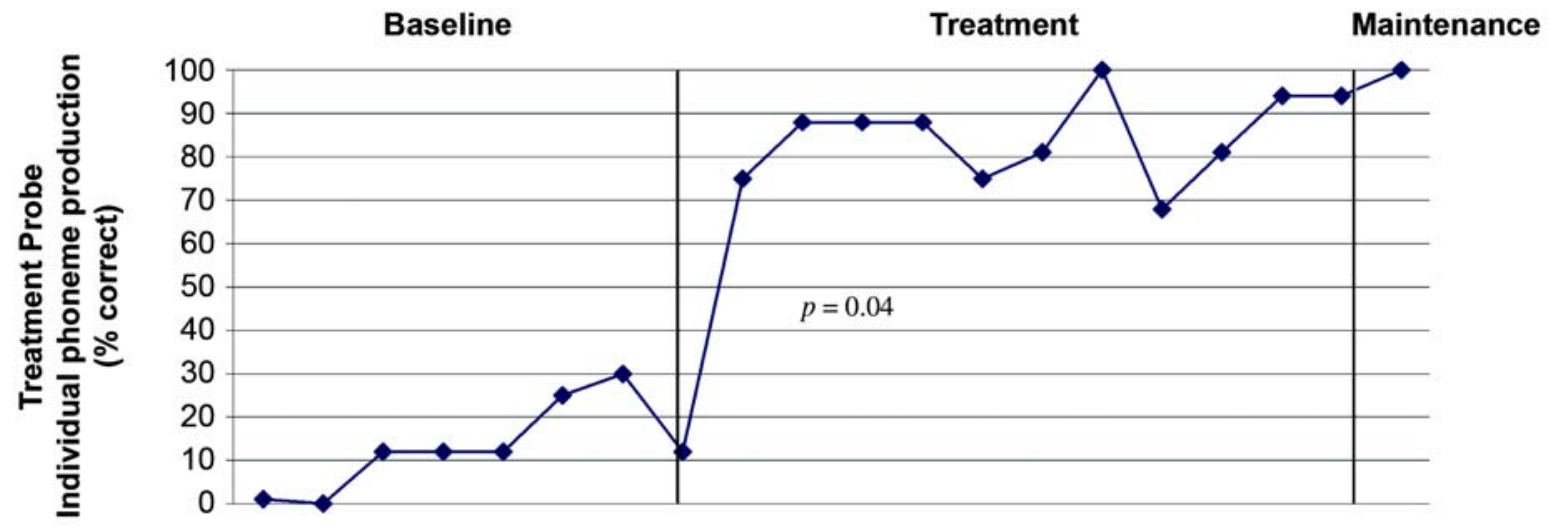

(b)

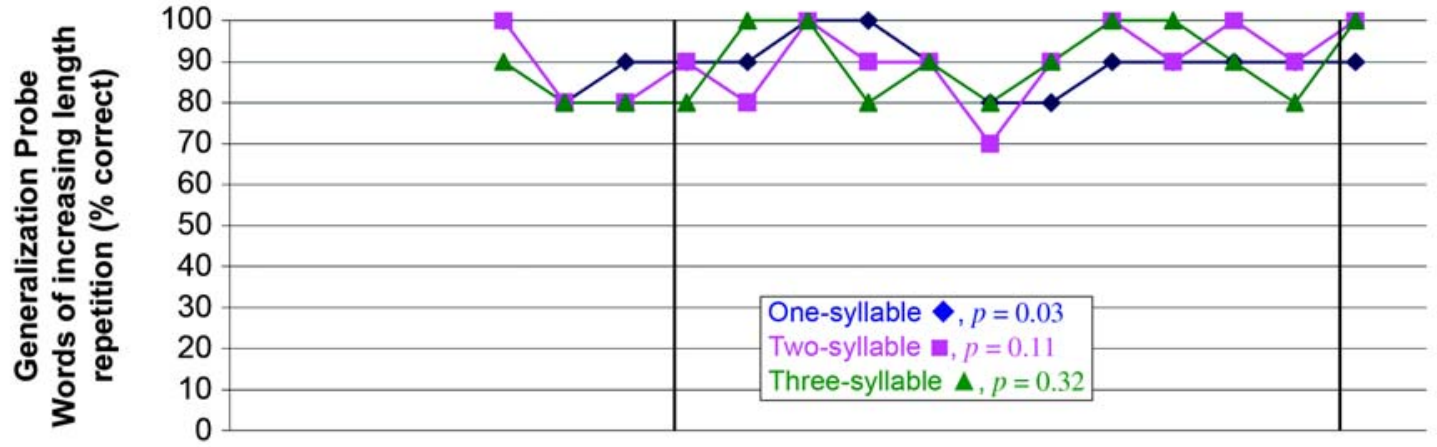

(c)

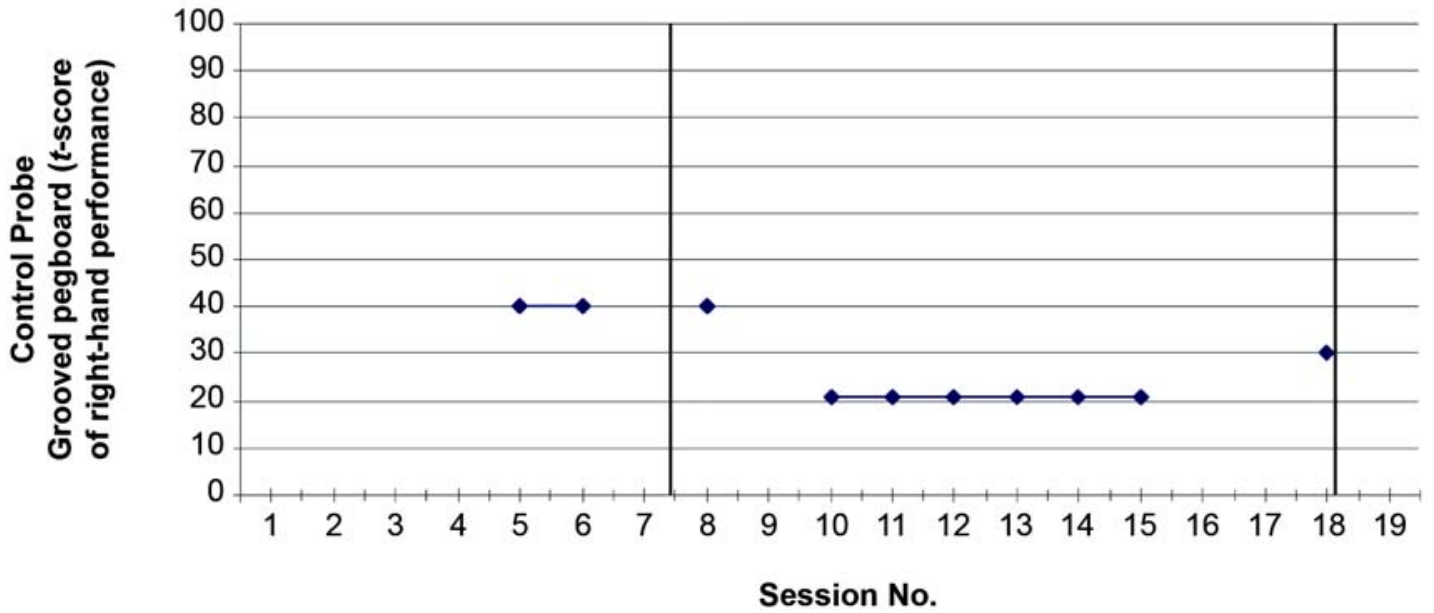

Figure 3.

Baseline, treatment, and maintenance data for (a) treatment, (b) generalization, and (c) control probes.

\section{Post Hoc Analysis}

Post hoc error analysis on words of increasing length and multisyllabic words was performed. Results showed the subject had a consistent inability to correctly produce phonemes $/ \mathrm{l} /, / \mathrm{r} /$, and $/ \mathrm{th} /$. Errors on these three sounds comprised 53 percent of total sound substitutions on repeated probes for repetition of words of increasing length and multisyllabic words. Post hoc analysis of treatment data revealed he mastered the ability to correctly produce these three sounds in isolation as well as in one- and two-syllable nonwords; however, the probe data showed that he was unable to produce these sounds in the context of real-word repetition. Specifically, errors on these sounds consisted of substitutions of /r/ for $/ \mathrm{l} / \mathrm{h} / \mathrm{w} /$ for $/ \mathrm{r} /$, and $/ \mathrm{ts} /$ for $/ \mathrm{th} /$. 
Table 3.

Results of repeated treatment, generalization, and control probes administered 8 times prior to initiation of treatment, weekly during treatment phase, and once 1-week posttreatment.

\begin{tabular}{|c|c|c|c|}
\hline Effect & Research Question & Dependent Measure & Results \\
\hline Treatment & $\begin{array}{l}\text { Does phonological treatment } \\
\text { improve subject's ability to } \\
\text { produce individual phonemes? }\end{array}$ & $\begin{array}{l}\text { Production of } 16 \text { phonemes } \\
\text { in isolation from line drawing } \\
\text { of articulators. }\end{array}$ & $p=0.03$ \\
\hline Generalization & $\begin{array}{l}\text { Does phonomotor treatment } \\
\text { generalize to repetition of } \\
\text { multisyllabic real words and } \\
\text { words of increasing length? }\end{array}$ & $\begin{array}{l}\text { Repetition of words of increasing } \\
\text { length and multisyllabic words } \\
\text { using phonetic transcription } \\
\text { to determine number of correctly } \\
\text { produced phonemes. }\end{array}$ & $\begin{array}{l}\text { Words of increasing length } \\
\text { repetition: one-syllable: } p=0.03 \text {; } \\
\text { two-syllable: } p=0.11 \text {; three } \\
\text { syllable: } p=0.32 \text {; multisyllabic } \\
\text { word repetition: } p=0.8 \text {. }\end{array}$ \\
\hline Generalization & $\begin{array}{l}\text { Does phonomotor treatment } \\
\text { generalize to measures of } \\
\text { perceptual judgment of } \\
\text { discourse production and } \\
\text { subject self-report? }\end{array}$ & $\begin{array}{l}\text { Perceptual judgment of } \\
\text { Brookshire Discourse Production } \\
\text { Pictures. Self-judgment rating } \\
\text { scale from 0-100. }\end{array}$ & $\begin{array}{l}\text { Slower rate, less effort. No } \\
\text { difference noted in prosody, } \\
\text { articulatory precision, content, } \\
\text { and overall intelligibility. Less } \\
\text { natural speech. Self-judgment: } \\
\text { less apprehension when speaking } \\
\text { with unfamiliar people, } 90 \% \\
\text { increase in telephone use, and 100\% } \\
\text { increase in ease communicating. }\end{array}$ \\
\hline
\end{tabular}

\section{DISCUSSION}

The purpose of this phase I rehabilitation study was to investigate the effects of an intensive phonomotor rehabilitation program on speech-language production in acquired AOS and aphasia. While this study has limitations (selection of generalization measures, single-subject design), the positive treatment outcome and improvement in some measures of ecological validity clearly indicate this line of research warrants further investigation.

\section{Research Question 1: Treatment Effects}

The first research question asked whether treatment improved the subject's ability to produce individual phonemes. Results showed that indeed our subject acquired this skill. Phoneme accuracy of at least 90 percent was required per minimal pair before introduction of additional pairs. A typical acquisition rate of minimal pair production was approximately 2 hours of treatment. The outcome data for this repeated probe were collected after every 8 hours of treatment. Therefore, we were not surprised that by the first probe (i.e., after 8 hours of treatment), our subject improved in phoneme production from an average of $2 / 16$ correct to $12 / 16$ correct (75\%) and by the second probe (i.e., after 16 hours of treatment) our subject was able to consistently produce 14/16 (88\%) phonemes correctly. By the second week of treatment, the two phoneme pairs consistently in error were those acquired most recently and therefore the ones with which the subject had had the least amount of practice with. By the end of the treatment program and one-week posttreatment assessment, the subject was able to spontaneously produce 15/16 and 16/16 phonemes correctly.

\section{Research Question 2: Generalization to Repetition of Multisyllabic Words}

The second research question asked whether phonomotor treatment would generalize to repetition of multisyllabic real words and words of increasing length. Treatment did not generalize to repetition of multisyllabic real words. One possible explanation for the lack of generalization may be a ceiling effect. Our subject had $>85$ percent accuracy in repetition of multisyllabic words (e.g., snowman, snowman, snowman) before the start of treatment, and scores remained in the range of 83 to 93 percent accuracy throughout treatment. In terms of repetition of words of increasing length, treatment generalized to repetition of one-syllable words only. This pattern of generalization could be attributed to the level of treatment accomplished. In particular, the treatment program is hierarchically arranged, with the subject progressing from nonword stimuli to individual phonemes to single nonword syllables to 
multiple nonword syllables. Because of the time-limited nature of this phase I trial, our subject progressed only to the point of five-phoneme one- and two-syllable nonword combinations. This level of progression may not have been adequate to warrant generalization past the point of onesyllable real words.

In 1970, Johns and Darley systematically analyzed phonemic characteristics of errors in 10 dysarthric speakers, 10 control subjects, and 10 individuals with AOS, and the error patterns of our subject were compatible with their results [15]. In particular, they found that $/ \mathrm{th} /, / \mathrm{r} /$, and /l/ were in error more often when compared with other sounds $(45 \%, 18 \%$, and $33 \%$, respectively). Also, they found that mode of presentation influenced error production. Auditory-visual mode of stimulus presentation produced fewer errors than repetition (e.g., auditory alone). Our subject showed fewer errors on these sounds when the stimuli were presented in an auditory-visual mode than when the stimuli were presented via repetition.

Finally, the change in repetition abilities detected posttreatment on the repetition subtest of the WAB is interesting. A modest improvement was noted posttreatment (79/100 to 98/100) on phrase and sentence repetition. These repetition results are consistent with a previous investigation in which we administered this treatment program to two individuals with acquired aphasia and AOS and reported improvement in posttreatment production skills for both subjects (WAB repetition subtest, WAB spontaneous speech subtest, and repeated measures for consonant repetition, nonword repetition, real-word repetition, and oral praxis) [7]. We discussed these results in the context of declarative and nondeclarative memory [7]. In particular, language involves information exchange between cortices supporting declarative (i.e., lexical-semantic) and nondeclarative (i.e., articulatory) memories. Adair et al. proposed that the "phonomotor rehabilitation program induced modifications at the declarative-procedural interface instantiating abstract symbolic entities (graphemes and graphemic sequences) as motor programs” [16].

\section{Research Question 3: Generalization to Measures of Discourse Production and Self-Report}

Discourse production was measured perceptually, and the subject completed a self-report questionnaire on communication behaviors. Perceptual judgment of discourse production showed no difference in prosody, articulatory precision, content, or overall intelligibility.
However, the subject was judged to speak with slower rate, less effort, and less naturalness posttreatment. We predicted slower rate and less effort, but would not have predicted his speech to be perceived as less natural. This is an interesting finding and warrants querying the judges for the particular aspects of naturalness to which they were responding.

Subject self-report indicated the subject experienced less apprehension toward speaking with unfamiliar people, a 90 percent increase in telephone use, and 100 percent improvement in communication ease. In other words, the subject judged himself to use the telephone 0 percent of the time at the start of treatment and 90 percent of the time at the end of treatment. For communication ease, he judged himself to have 0 percent ease at the start of treatment and 100 percent ease at the end of treatment.

We predicted that he would report improvement in his speech. Clinicians often see patients who perceive change when they are clearly changing on laboratory measures and not showing generalization to impairment-level measures. A reflexive interpretation of this phenomenon is that patients are not reliable; they do not want to hurt the therapist's feelings or they are showing a placebo effect. We propose a fourth interpretation based on the possibility that patients do understand something about changes. Perhaps we need to devote time to identifying and understanding the particular aspects by which the patient judges those changes, rather than trying to explain them away.

\section{CONCLUSIONS}

The treatment in this phase I clinical study was designed to incorporate principles of motor learning. During the acquisition phase, Schmidt and Bjork recommend varied stimuli, random practice, mental practice, and a short delay for KR and KP [5]. We incorporated these strategies and saw consistent improvement on daily therapy tasks, gains on posttreatment measures, and a perception of significant improvement by the subject, despite limited changes on generalization measures. While this lack of generalization may be because of various aspects of the treatment paradigm, we propose that the outcome measure (repetition of multisyllabic real words) was a poor choice and should be modified in future studies. Instead, generalization measures could potentially include the use of stimulus modalities in addition to repetition (e.g., visual) and multisyllabic nonwords (to avoid 
lexical-semantic processing). Further research along these lines should include replication in additional subjects and should also focus on phase II goals to define the appropriate population, examine treatment dosage, and refine outcome measures.

\section{ACKNOWLEDGMENTS}

We would like to thank the subject for his participation in the study.

Dr. Diane Kendall is now with the Department of Communication Sciences and Disorders, University of Florida, Gainesville, Florida.

This material was based on work supported by the VA Rehabilitation Research and Development (RR\&D) Brain Rehabilitation Research Center, a VA RR\&D Associate Investigator Award (grant C2438H), a National Institutes of Health award (grant P50-DC03888), and VA RR\&D Career Research Development Awards (grant C2743V and B3480H).

The authors have declared that no competing interests exist.

\section{REFERENCES}

1. McNeil MR. Clinical management of sensorimotor speech disorders. New York (NY): Thieme; 1997. p. 329.

2. Duffy JR. Motor speech disorders: Substrates, differential diagnosis, and management. St. Louis (MO): Elsevier Mosby; 2005. p. 1-578.

3. Rosenbek JC, Lemme ML, Ahern MB, Harris EH, Wertz RT. A treatment for apraxia of speech in adults. J Speech Hear Disord. 1973;38(4):462-72. [PMID: 4754879]

4. Wambaugh JL. A summary of treatments for apraxia of speech and review of replicated approaches. Semin Speech Lang. 2002;23(4):293-308. [PMID: 12461728]
5. Schmidt RA, Bjork RA. New conceptualizations of practice: Common principles in three paradigms suggest new concepts for training. Psychol Sci. 1992;3(4):207.

6. Lindamood PC, Lindamood PD. The Lindamood Phoneme Sequencing Program for reading, spelling, and speech. 3rd ed. Austin (TX): PRO-ED Inc; 1993.

7. Kendall DL, Conway TW, Rosenbek JC, Gonzalez-Rothi LJ. Phonological rehabilitation of acquired phonologic alexia. Aphasiology. 2003;17(11):1073-96.

8. Kertesz A. The Western Aphasia Battery. New York (NY): Psychological Corporation; 1982.

9. Nicholas LE, Brookshire RH. A system for quantifying the informativeness and efficiency of the connected speech of adults with aphasia. J Speech Hear Res. 1993;36(2):338-50. [PMID: 8487525]

10. Crosbie J. Interrupted time-series analysis with brief singlesubject data. J Consult Clin Psychol. 1993;61(6):966-74. [PMID: 8113497]

11. Kaplan E, Goodglass H, Weintraub S. The Boston Naming Test. Philadelphia (PA): Lippincott Williams \& Wilkins; 1983.

12. Howard D, Patterson KE. The Pyramids and Palm Trees Test. Bury St. Edmunds (England): Thames Valley Test Company; 1992.

13. Wagner RK, Torgesen JK, Alexander C. The Comprehensive Test of Phonological Processing. Austin (TX): PROED Inc; 1999.

14. Lindamood CH. Lindamood Auditory Conceptualization test. Austin (TX): Teaching Resources; 1971.

15. Johns DF, Darley FL. Phonemic variability in apraxia of speech. J Speech Hear Res. 1970;13(3):556-83. [PMID: 5507115$]$

16. Adair JC, Nadeau SE, Conway TW, Gonzalez Rothi LJ, Heilman PC, Green IA, Heilman KM. Alterations in the functional anatomy of reading induced by rehabilitation of an alexic patient. Neuropsychiatry Neuropsychol Behav Neurol. 2000;13(4):303-11. [PMID: 11186167]

Submitted for publication November 28, 2005. Accepted in revised form June 12, 2006. 